\title{
Role of Video Recording in Quality Assurance of Emergency Medical Services.
}

\author{
${ }^{1}$ Dr AbhinavWankar, ${ }^{2}$ Dr (Prof) PulijalaSatyanarayana \\ ${ }^{I}$ Diplomate of National Board ,Yashoda Hospital, Secunderabad, ${ }^{2}$ HOD Hospital Administration Yashoda \\ Hospital, Secunderabad - 500003 \\ ${ }^{1,2}$ Role of Video Recording in Quality Assurance of Emergency Medical Services
}

\begin{abstract}
Video recording is widely used for varied purposes in Emergency Department. It is used to assess interpersonal and non-verbal communications which are often difficult to monitor by other means. Optimum care of emergency patients requires rapid assessment and treatment and investigation with a correct order of priorities. Other than by

Stationing a skilled observer in the reception area with notebook and stop-watch,

Video recording offers the only way to assess whether the objectives are obtained. The camera is set to automatically date and time stamp and so it is easy to establish how long it takes for personnel to attend, and to time clinical procedures required during the care of critically ill patients. The video-recordings enable a sharing of valuable experience and this produces a definite improvement in the emergency medical services. Round the clock monitoring through video recording can improve quality of care given to emergency room patients drastically.

In our study, Following Quality Indicators of Emergency Department were monitored through video recording-

1. Internal transportation,

2. Time to triage,

3. Response times (ER staff; Registrars; Consultants)

4. Turn Around Time incidents (Including diagnostics, Patient Safety \& Work-related Incidents)

5. Delays in Shifting

6. Lama Handling process

7. MLCs, effective handling of disputes on delays related to the patient care

8. Brought dead, \& Deaths handling process

9. Duration in the Emergency Department

10. Clinical Indicators
\end{abstract}

Video clippings were reviewed by our Consultants and Senior Registrars, and subsequently reviewed with our Administrators during audit and teaching sessions.

Total of 500 patients coming to Emergency Room were observed between Jan 2013 to March 2013.It was observed that 194(38.8\%) patients were brought in ER on wheel chair, 270(54\%) patients were brought on stretcher while 36(7.2\%) patients were walk in patients.171 (34.2\%) patients had violation of Triage Time. Response Times (ER staff; Registrars; Consultants) were non compliant in 137(27.4\%) patients.TAT was non compliant in $9.2 \%$ of tests.43 (8.6\%) patients had delay in shifting. No untoward incident was observed in handling MLCs, death and brought dead.

Our study aims to utilize Video recording of Emergency room team as an effective quality improvement tool to evaluate Emergency Room performance, psycho-motor skills and techniques, and to identify educational/ training needs related to specific procedures.Our Study also aims to utilize Video recording of Emergency room team as an effective tool for improving emergency team performance by educating clinical staff regarding roles and responsibilities.

Key Words

Emergency Room-ER

Video Recording

Quality Indicators

Emergency Room Performance

Time of Triage

Response Times

Turn Around Time

\section{Introduction}

In today's India, with the increases in the aging population and patients'demand for new medical services, medical science and technology is developing muchfaster than ever before. However, in the health care 
delivery system it is normallydifficult to ensure that applications which quickly follow from those developments areimplemented with full attention given to their safety [1].

Video recording is widely used for varied purposes in Emergency Department. It is used to assess interpersonal and non-verbal communications which are often difficult to monitor by other means. Optimum care of emergency patients requires rapid assessment and treatment and investigation with a correct order of priorities. Other than by Stationing a skilled observer in the reception area with notebook and stop-watch.

Video recording offers the only way to assess whether the objectives are obtained. The camera is set to automatically date and time stamp and so it is easy to establish how long it takes for personnel to attend, and to time clinical procedures required during the care of critically ill patients. The video-recordings enable a sharing of valuable experience and this produces a definite improvement in the emergency medical services.. The digital camera, which captures high resolution colour images that can be individually computer edited and enhanced provides exciting possibilities for photographic presentation in the future. A system for video recording resuscitations can be readily installed and used for quality improvement.

Round the clock monitoring through video recording can improve quality of care given to emergency room patients drastically.

\section{Review of Literature}

In Europe, many EDs have undergone organizational changes 1.2 . Hospitals receiving acute patients are increasingly merged to larger organizations. Continuous high expertise in the EDs is promoted through the presence of relevant resources, medical specialties and experienced staff ${ }^{2}$. In Denmark, the new concept behind EDs consists of merging all acute admission units and observatory units into one joint ED. The rationale for restructuring is first and foremost to cope with an increased amount of patients while securing delivery of high quality and efficiency, concurrently with decreased overall hospital capacity $\stackrel{3}{ }$. Promotion of interdisciplinary teamwork and earlier senior physician involvement are examples of means to deliver timely and high quality treatment to patients within the EDs, which is essential for early diagnosis and provision of effective treatment

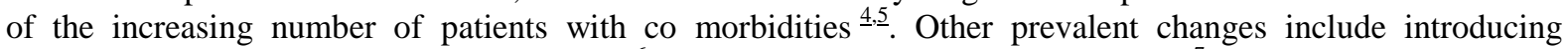
emergency medicine as a separate specialty ${ }^{6}$ and formalized use of triage systems ${ }^{7}$. Many different ways of organizing the ED is evolving and the costs and effects are being debated ${ }^{\stackrel{8}{*}}$. A way of assessing the effect on the re-organization and the many local initiatives is highly warranted.

Inspired by the private service sector's way of monitoring and evaluating work processes, health care

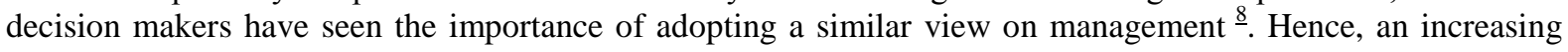
number of quality- and performance measurement initiatives have been integrated within the core operations. Performance measurement is a broad topic, which is rarely defined in detail. Most commonly, it is referred to as the process of quantifying actions, where measurement is a process of quantification and following action leads to performance ${ }^{9}$. Individual performance measures are defined as metrics that reflect effectiveness and/or efficiency of an action. A selection of such performance measures thus comprises of a performance measurement system which enables a more comprehensive evaluation of performance. Widely acknowledged performance measurement frameworks such as the Balanced Scorecard $\stackrel{10}{ }$ and Business Excellence $\stackrel{11}{ }$ have been implemented in health care to assure strategy alignment with operations. Even though a high percentage of performance measurements initiatives fail, mainly due to either being poorly designed or too difficult to implement in practice ${ }^{12}$, successful implementation and use has been reported $\underline{13,14}$.

The fundamental idea of quality assurance in health care was originally to pass accreditations, whereas the healthcare sector now strives to converge quality improvements wherever possible. Many EDs have accepted the Institute of Medicine's (IOM) report from 2001 called "Crossing the Quality Chasm" ${ }^{15}$. In this report, six quality domains are endorsed. These are safety,effectiveness, patientcenteredness, timeliness, efficiency and fairness (equity). The termsefficiency and effectiveness are often used interchangeably. Efficiency refers to the effectiveness of specific procedures whereas effectiveness regards the total outcome $\frac{15}{\text {. }}$.

Different initiatives are continuously being presented in EDs in response to the IOM domains. In the United Kingdom (UK), crowded EDs were sought resolved by the introduction of the four hour target as a primary performance measure $\frac{16}{}$. This means that only $98 \%$ of the patients may stay within the ED for more than four hours.

Focus on a single time-related measure does not necessarily correspond to high levels of quality and can potentially lead to dysfunctional behavior ${ }^{17}$. Other important performance areas become unmonitored when focusing only on few ultimate measures. As an example, patients are without adequate treatment transferred to other wards more rapidly to keep length of stay in the ED within the accepted upper threshold limits. This can lead to reduced quality, increased costs and difficulties in retaining staff (sustainability). The outcome of the measure would be great yet the obtained quality would be poor.

Asking the clinicians in UK EDs about the subsequent effects of the four hour target resulted in a 
governmental report in which a total of eight performance measures to best represent quality were suggested by

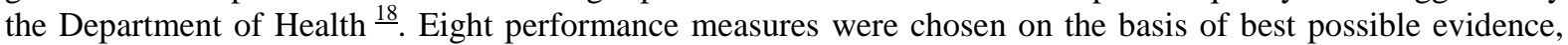
formulated by lay-representatives and are weighted equally (in theory).

The UK EDs are not alone in the dilemma of determining how to evaluate new initiatives on key performance measures aligned with department visions. Similar problems such as crowding and scarce resources are struggled with elsewhere in the world. The selection of which performance measures to highlight also differs according to stakeholder perspective ${ }^{19}$. A clinician's perspective on highly important performance measures is distinct compared to that of a patient, policy maker, or administrator, mainly due to the use of the measures for varying purposes. The entities may be subject to alteration over time depending on evolving clinical evidence, new practices and procedures, public opinions, and health system dynamics. Whereas a policy maker's chief concern involves public accountability or a measurement framework reflecting 'pay for performance', the clinicians will demand procedural improvements for the benefit of enhanced treatment outcomes and clinical safety. From a patient's perspective, the main focus will be on patient centeredness considered excellent medical treatment is delivered.

Consensus is still lacking on which measures are considered to be most accurate, extensive, clearly defined, and based on evidence $\underline{20,21}$. Working towards a consensus of performance measures that reflect the general performance of an ED and whether or not certain quality improvement initiatives prove efficient is clearly warranted. A shared understanding of performance measures will enable continuous quality improvements and benchmarking opportunities both internally and externally over time.

The aim of this article is to present an overview of the highlighted performance measures suggested in internationally peer-reviewed review articles through the application of PRISMA guidelines.

\section{Aims and Objectives}

Aims

1) Our study aims to utilize Video recording of Emergency room team as an effective quality improvement tool to evaluate Emergency Room performance, psycho-motor skills and techniques.

2) To identify educational/ training needs related to specific procedures.

3) Our Study also aims to utilize Video recording of Emergency room team as an effective tool for improving emergency team performance by educating clinical staff regarding roles and responsibilities.

\section{Objectives}

1) To identify a set of quality indicators that measure the quality of Emergency Room, combining structure, process and outcome indicators.

2) To gain insight into the barriers and success factors that affected the quality of care in emergency room.

3) To identify areas for quality improvement in emergency room.

4) To describe, map, and critically evaluate which performance measures are important in quality of care in emergency room.

\section{Materials and Methods}

In our study,video recordings of Emergency Room from different cameras installed in Emergency Room were studied. It also recorded sound through an integral or remotemicrophone. Pictures can be replayed through a standard video recorder.

With the camera set for wide-angle filming it can capture almost the entireroom. It has been mounted on a camera mount and boxed in for security purposes.

It films through a one way mirror. The camera is positioned behind the patient's

head to maintain anonymity.

We undertook recordings randomly .The camera would run for a maximum of $24 \mathrm{hrs}$.

In our study, Following Quality Indicators of Emergency Department were monitored through video recording-

1. Mode of Transport

2. Time to triage,

3. Response times (ER staff; Registrars; Consultants)

4. Turn Around Time incidents (Including diagnostics, Patient Safety \& Work-related Incidents)

5. Delays in Shifting

6. Lama Handling process

7. MLCs, effective handling of disputes on delays related to the patient care

8. Brought dead, \& Deaths handling process

9. Duration in the Emergency Department

Video clippings were reviewed by our Consultants and Senior Registrars, and subsequently reviewed with 
our Administrators during audit and teaching sessions. Total of 500 patients coming to Emergency Room were observed between Jan 2013 to March 2013.

Sample Size-500 Emergency Room patients

Duration-From Jan 2013 to March 2013

Inclusion Criteria-

Patients coming to emergency room and getting admitted

\section{Exclusion Criteria}

1. Patients coming to emergency room only as a referral.

2. Patients coming to emergency room for procedures like taking injections, nebulization.

3. Patients coming to Emergency Room for OP basis treatment.

\section{Observations}

1) Mode of Transport

It was observed that 194(38.8\%) patients were brought in ER on wheel chair, 270(54\%) patients were brought on stretcher while $36(7.2 \%)$ patients were walk in patients

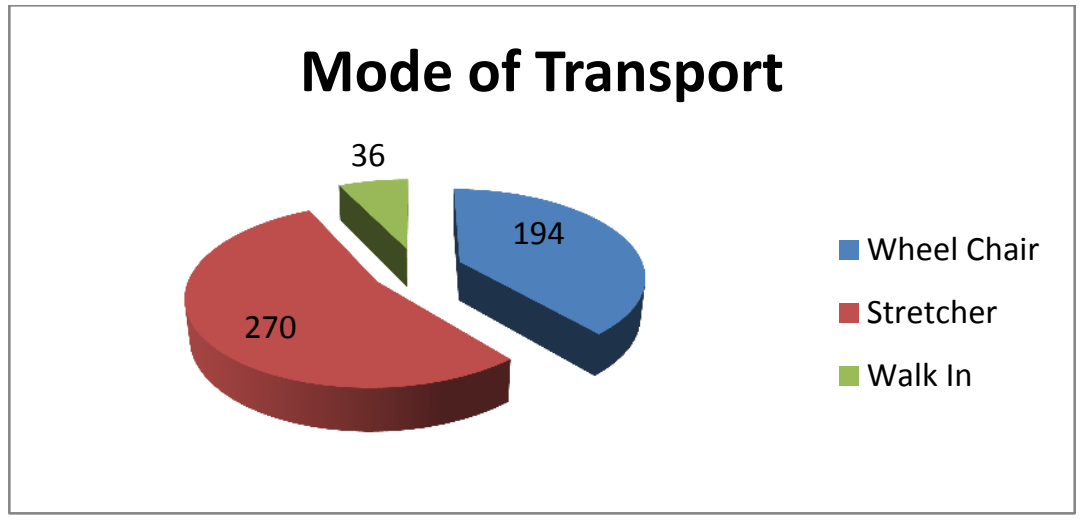

Table No 1

\section{2) Triage Time}

Out of 500 patients observed, $171(34.2 \%)$ patients had violation of Triage Time. 2 mins Triage time was taken as standard.Above 2 mins were taken as violation.

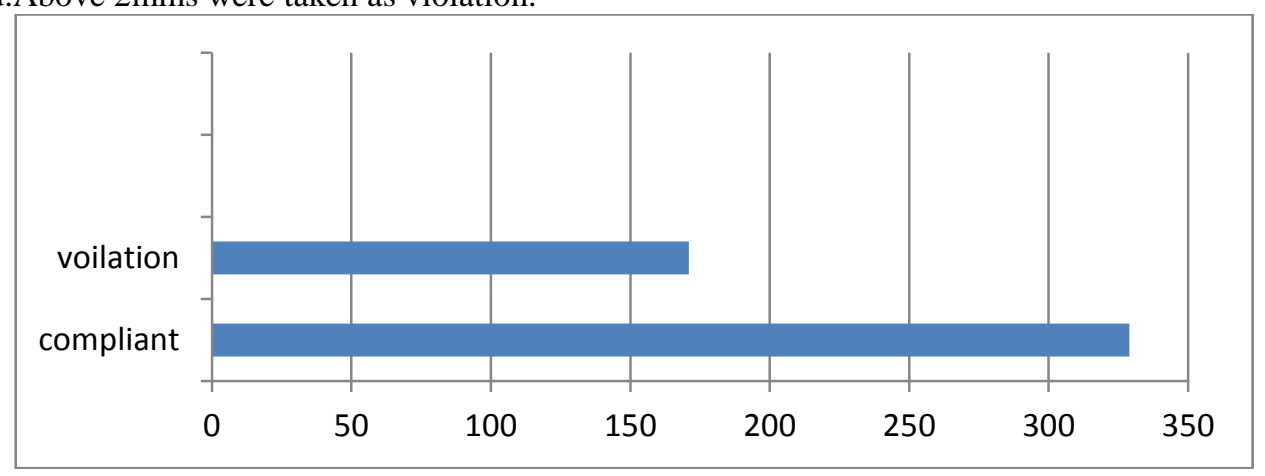

Table No 2 Triage Time

\section{3) Response times (Consultants; ER Physicians; Registrars)}

Out of 500 patients observed in Emergency Room, non compliance was found in 137(27.4\%) patients.5 mins was taken as standard response time. 


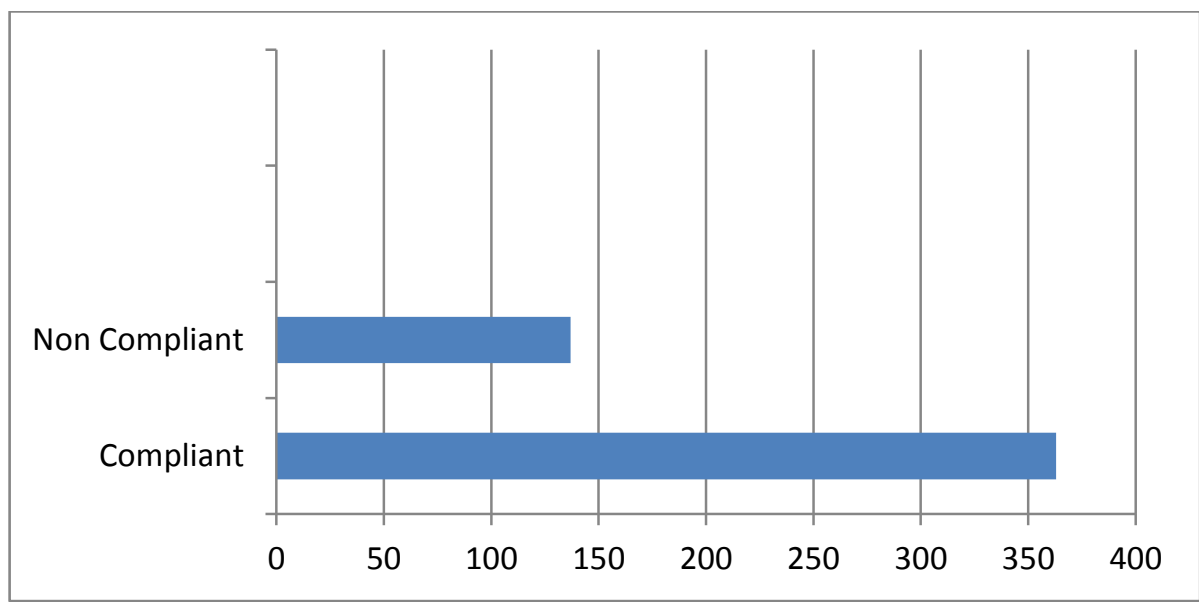

Table 3-Response Times of ER Physician, Consultant, Registrar

\section{4) TurnAround Time in Emergency Room}

Out of the total 500 patients observed in Emergency Room. Turn Around time was non compliantin 9.2\% of tests. 1 hour was taken as standard Turn Around Time.

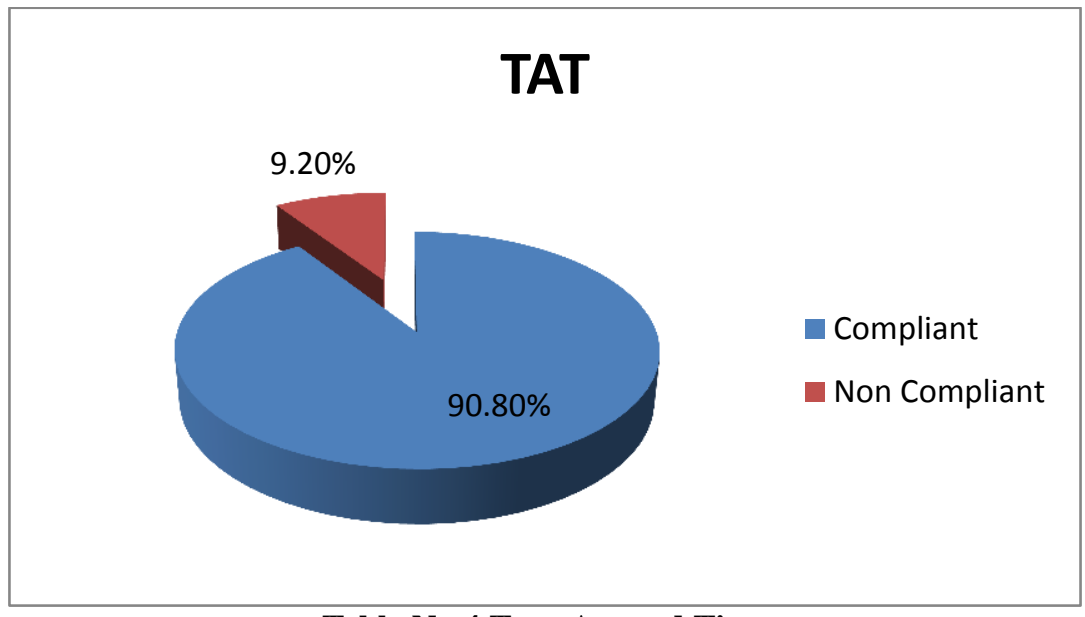

Table No 4.Turn Around Time

\section{5) Delay in shifting}

Out of the total 500 patients, $43(8.6 \%)$ patients had delay in shifting.4 hours of emergency room stay was taken as standard.

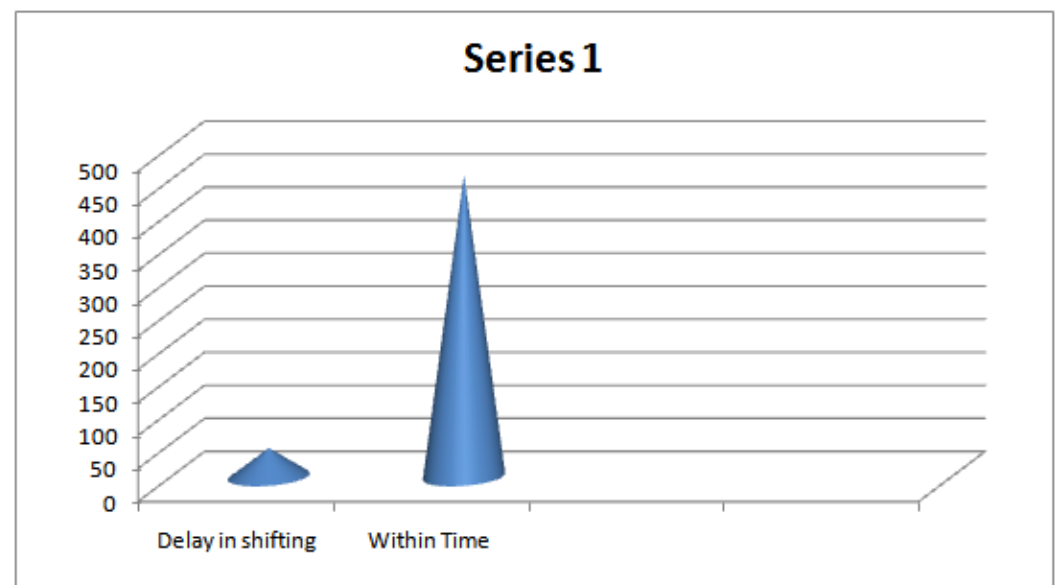

Table No 5 Delay in shifting

5) No untoward incident was observed in handling MLCs, death and brought dead. 


\section{Result}

1) $270(54 \%)$ patients were brought on stretcher.Hence a majority of patients coming to Emergency Room are brought on stretcher.

2) $171(34.2 \%)$ patients had violation of Triage time.Hence there is a significant delay in Triage Time

3) Response Times (ER staff; Registrars; Consultants) were non compliant in 137(27.4\%) patients. There is a $27.4 \%$ delay in response times.

4) TAT was non compliant in $9.2 \%$ of tests. Turn around shows a significant delay in reporting

5) $43(8.6 \%)$ patients had delay in shifting. 43 patients had a prolonged hospital stay of more than 4 hours.

6) . No untoward incident was observed in handling MLCs, death and brought dead.

\section{Acceptance of video-recording}

\section{Discussion}

Video-recording, although increasingly widespread, is often disliked and resented

as a 'spy on the wall'. Reluctance on the part of both medical and nursing staff to participate in our experiment was however allayed after much discussion. Guidelines limiting the viewing of the material to initial review by senior medical staff. The erasure of recorded material within 1 week was accepted. This inevitably restricts sequential comparison of material, and limited formal study, but had to be accepted to gain staff cooperation.

The primary objective of study is to analyze, discuss, or promote a series of performance measures that reflect key performance metrics and quality-in-care in emergency departments.

No literature older than ten years that reviews overall ED performance measures was found. During the recent five years, there has been an intensified debate on ED performance measurement. This comes in response to a previous low prioritization of the emergency medicine area and an increase in ED patient volume over recent years. The performance measures are independent on patient specific indicators and thus serve to reflect overall ED performance levels.A joint set of identically defined performance measures across EDs would be beneficial in terms of benchmarking and ultimately continuous quality improvements. Further studies should investigate the interconnectivity between the selected performance measures. Insight into the performance measures' mutual impact allows for better understanding of ED performance.

\section{Recommendations}

1. More training of staff including nursing, doctors, housekeeping regarding different life saving procedures

2. Training to transportation staff regarding correct steps used for transporting

3. Qualitative approach in choosing performance measures is important. Especially the Delphi technique seeking consensus through either audits or questionnaires serves as a means to filter suggestions into core performance measures best suitable for ED assessments.

4. A set of performance measures should preferably be maintained over time to obtain sufficient data to add statistical strength, validity and reliability to each measure.

5. Clinicians and Administrators develop an ambulatory care change management team as part of a Quality Indicator delivery programme.

6. Optimize ED and informatics systems to collect the right data.

7. Recognize the Emergency Department as the hub of the delivery of emergency care and ensure that the necessary workforce is in place.

8. Review the processes to ensure flow which will involve early access to senior clinical decision makers, supported by prompt access to diagnostics including pathology and imaging

9. To undertake a careful bed requirement analysis to ensure that the pre-empted capacity is available to meet anticipated demand.

10. Analyzing the nature of attendance patterns and demands, to enable planning for sufficient staffing. Identification of staff that will perform this role.

11. Development of enabling pathways to assist with requesting of investigations and administration of early analgesia.

12. Regular academic classes have to be conducted by doctor \& nursing instructors to improve the knowledge of Nursing Staff.

13. Allowing strictly any 1 attendant with the patient to avoid overcrowding

14. More prompt response from Emergency Room Physician, Registrars, Consultants. This will improve triage time and response times which is a very important component of quality assurance

15. Emergency laboratory investigations and radiological investigations ,if feasible be performed in emergency room itself. 
11] Alberti G:Transforming emergency care in England. 2005.

\section{Bibliography}

http://aace.org.uk/wp-content/uploads/2011/11/Transforming-Emergency-Care-in-ngland.pdf website

[2] Danish Health and Medicines Authority:Styrketakutberedskab - planlægningsgrundlag for detregionalesundhedsvæsen. 2007. http://www.sst.dk/publ/publ2007/plan/akutberedskab/styrketakutberedskab.pdf website

[3] Solberg LI, Asplin BR, Weinick RM, Magid DJ: Emergency department crowding: consensus development of potential measures.Ann Emerg Med 2003, 42(6):824-834. PubMed Abstract | Publisher Full Text

[4] Walley P, Silvester K, Mountford S: Health-care process improvement decisions: a systems perspective.Int J Health Care QualAssur 2006, 19(1):93-104. Publisher Full Text

[5] Shetty A, Gunja N, Byth K, Vukasovic M: Senior streaming assessment further evaluation after Triage zone: a novel model of care encompassing various emergency department throughput measures.Emerg Med Australas 2012, 24(4):374382. PubMed Abstract | Publisher Full Text

[6] Hallas P, Ekelund U, Bjornsen LP, Brabrand M: Hoping for a domino effect: a new specialty in Sweden is a breath of fresh air for the development of Scandinavian emergency medicine.SJTREM 2013, 21(1):26. PubMed Abstract | Publisher Full Text | PubMed Central Full Text

[7] Göransson KE, Ehrenberg A, Ehnfors M: Triage in emergency departments: national survey.J Clin Nurs 2005, 14(9):10671074. PubMed Abstract | Publisher Full Text

[8] Graff L, Stevens C, Spaite D, Foody J: Measuring and improving quality in emergency medicine. AcadEmerg Med 2002, 9(11):1091-1107. PubMed Abstract | Publisher Full Text

[9] Neely A, Gregory M, Platts K: Performance measurement system design: a literature review and research agenda.IJOPM 2005, 25(12):1228-1263.

[10] Kaplan RS, Norton DP: The balanced scorecard: measures that drive performance.Harv Bus Rev (USA) 2005, 83(7):172-180.

[11] Nicolay CR, Purkayastha S, Greenhalgh A, Benn J, Chaturvedi S, Phillips N, Darzi A:Systematic review of the application of quality improvement methodologies from the manufacturing industry to surgical healthcare.Br J Surg 2012,99(3):324335. PubMed Abstract | Publisher Full Text

[12] Neely A, Bourne M: Why measurement initatives fail.MBE 2000, 4(4):3-7.

[13] Huang S, Chen P, Yang M, Chang W, Lee H: Using a balanced scorecard to improve the performance of an emergency department.Nurs Econ 2004, 22(3):140-146. PubMed Abstract

[14] Samani DZ, Kohan MZ: Framework for implementing balanced scorecard in hospitals.JIBED 2011, 5(4):362368. Publisher Full Text

[15] Alessandrini EA, Knapp J: Measuring quality in pediatric emergency care.ClinPedEmerg Med 2011, 12(2):102112. Publisher Full Text

[16] Coleman P, Nicholl J: Consensus methods to identify a set of potential performance indicators for systems of emergency and urgent care.J Health Serv Res Policy 2010, 15:12-18. PubMed Abstract | Publisher Full Text

[17] Kelman S, Friedman JN: Performance improvement and performance dysfunction: an empirical examination of distortionary impacts of the emergency room wait-time target in the English National Health Service.JPART 2009, 19(4):917-946.

[18] Department of Health:A\&E Clinical Quality Indicators - data definitions. 2011. http://www.fadelibrary.org.uk/wp/wp-content/uploads/downloads/2011/09/AE-clinical-quality-indicators-datadefinitions.pdf webcite

[19] Cameron PA, Schull MJ, Cooke MW: A framework for measuring quality in the emergency department.Emerg Med J 2011, 28(9):735-740. PubMed Abstract | Publisher Full Text

[20] Lindsay P, Schull M, Bronskill S, Anderson G: The development of indicators to measure the quality of clinical care in emergency $\begin{array}{lllll}\text { departments following a modified-Delphi approach.AcadEmerg } & \end{array}$ 1139. PubMed Abstract | Publisher Full Text

[21] Schull MJ, Guttmann A, Leaver CA, Vermeulen M, Hatcher CM, Rowe BH, Zwarenstein M, Anderson GM: Prioritizing performance measurement for emergency department care: consensus on evidence-based quality of care indicators.CJEM 2011, 13(5):300-309. PubMed Abstract | Publisher Full Text

[22] Moher D, Liberati A, Tetzlaff J, Altman DG: Preferred reporting items for systematic reviews and meta-analyses: the PRISMA statement.Int J Surg 2010, 8(5):336-341. PubMed Abstract | Publisher Full Text

[23] Traberg A: Management-By-Objectives in Healthcare. Technical University of Denmark: DTU Management Engineering; 2011. [PhD Thesis]

[24] Persell SD, Kaiser D, Dolan NC, Andrews B, Levi S, Khandekar J, Gavagan T, Thompson JA, Friesema EM, Baker DW: Changes in performance after implementation of a multifaceted electronic-health-record-based quality improvement system.Med Care 2011, 49(2):117-125. PubMed Abstract | Publisher Full Text

[25] Stelfox HT, Bobranska-Artiuch B, Nathens A, Straus SE: A systematic review of quality indicators for evaluating pediatric trauma care.Crit Care Med 2010, 38(4):1187-1196. PubMed Abstract | Publisher Full Text

[26] Stelfox HT, Straus SE, Nathens A, Bobranska-Artiuch B: Evidence for quality indicators to evaluate adult trauma care: a systematic review.Crit Care Med 2011, 39(4):846-859. PubMed Abstract | Publisher Full Text

[27] Pines JM, Fermann GJ, Ferroggiaro AA, Irvin CB, Mazer M, Frank Peacock W, Schuur JD, Weber EJ, Pollack CV: The role of the society for academic emergency medicine in the development of guidelines and performance measures.AcadEmerg Med 2010, 17(11):e130-e140. PubMed Abstract | Publisher Full Text

[28] Baker DW, Qaseem A: Evidence-based performance measures: preventing unintended consequences of quality measurement.Ann Intern Med 2011, 155(9):638-640. PubMed Abstract | Publisher Full Text

[29] Beniuk K, Boyle AA, Clarkson PJ: Emergency department crowding: prioritising quantified crowding measures using a Delphi study.Emerg Med J 2012, 29(11):868-871. PubMed Abstract | Publisher Full Text

[30] Hung GR, Chalut D: A consensus-established set of important indicators of pediatric emergency department performance.PediatrEmerg Care 2008, 24(1):9-15. PubMed Abstract | Publisher Full Text

[31] Guttmann A, Razzaq A, Lindsay P, Zagorski B, Anderson G: Development of measures of the quality of emergency department care for children using a structured panel process.Pediatrics 2006, 118(1):114-123. PubMed Abstract | Publisher Full Text

[32] Welch SJ, Asplin BR, Stone-Griffith S, Davidson SJ, Augustine J, Schuur J: Emergency department operational metrics, measures and definitions: results of the second performance measures and benchmarking summit.Ann Emerg Med 2011,58(1):3340. PubMed Abstract | Publisher Full Text 
[33] McClelland MS, Jones K, Siegel B, Pines JM: A field test of time-based emergency department quality measures.Ann Emerg Med 2012, 59(1):1-10.e2PubMed Abstract | Publisher Full Text

[34] Ekelund U, Kurland L, Eklund F, Torkki P, Letterstål A, Lindmarker P, Castrén M: Patient throughput times and inflow patterns in Swedish emergency departments. A basis for ANSWER, A National SWedish emergency registry.SJTREM 2011, 19(1):1937. PubMed Abstract | Publisher Full Text | PubMed Central Full Text

[35] Heyworth J: Emergency medicine - quality indicators: the United Kingdom perspective.AcadEmerg Med 2011, 18(12):12391241. PubMed Abstract | Publisher Full Text

[36] Sibbritt D, Isbister GK, Walker R: Emergency department performance indicators that encompass the patient journey.QualManag Health Care 2006, 15(1):27-38. PubMed Abstract | Publisher Full Text

[37] Boudreaux ED, O'Hea EL: Patient satisfaction in the emergency department: a review of the literature and implications for practice.J Emerg Med 2004, 26(1):13-26. PubMed Abstract | Publisher Full Text

[38] Muntlin $\AA$, Gunningberg L, Carlsson M: Patients' perceptions of quality of care at an emergency department and identification of areas for quality improvement.J Clin Nurs 2006, 15(8):1045-1056. PubMed Abstract | Publisher Full Text

[39] Göransson KE, von Rosen A: Patient experience of the triage encounter in a Swedish emergency department.IntEmergNurs 2010, 18(1):36-40. PubMed Abstract | Publisher Full Text

[40] Crouch R, Cooke M: Making care count: introducing the emergency department quality indicators.IntEmergNurs 2011, 19(2):6768. PubMed Abstract

[41] Lin BYJ, Wan TTH, Hsu CC, Hung F, Juan C, Lin C: Relationships of hospital-based emergency department culture to work satisfaction and intent to leave of emergency physicians and nurses.Health Serv Manage Res 2012, 25(2):6877. PubMed Abstract | Publisher Full Text

[42] Benneyan JC, Lloyd RC, Plsek PE: Statistical process control as a tool for research and healthcare improvement.QualSaf Health Care 2003, 12(6):458-464. PubMed Abstract | Publisher Full Text |PubMed Central Full Text

[43] Gordon BD, Flottemesch TJ, Asplin BR: Accuracy of staff-initiated emergency department tracking system timestamps in identifying actual event times.Ann Emerg Med 2008, 52(5):504-511. PubMed Abstract | Publisher Full Text

[44] Jones P, Schimanski K: The four hour target to reduce emergency department 'waiting time': a systematic review of clinical outcomes.Emerg Med Australas 2010, 22(5):391-398. PubMed Abstract | Publisher Full Text 45.Peltier L. F., Geertsma R. H. \&Youmans R. L. (1969) Television Videotape Recording: An adjunct in teaching Emergency Medical Care. Surgery 66, 233236.46.Hoyt D. B., Shackford S. R., Fridlnd D. H. et al. (1988) Videorecording Trauma Resuscitations: an effective teaching technique. The Journal of Trauma 28, 435-440. 